\title{
The Impact of Information Competencies on Socio-Economic Development in Southern Hemisphere Economies*
}

Jesus Lau, Ph.D., USBI Veracruz Library, Universidad Veracruzana

\begin{abstract}
This paper discusses the North-South knowledge gap and its relationship to socioeconomic and information development, education, and information literacy. Information development-the information progress of a country-is analyzed using indicators of production, storage, and demand of recorded information/knowledge. Most concepts are discussed from the point of view of developing countries, nations that basically fall within the Southern Hemisphere. The term developing economies is used to group middle-, low-, and lowest-income nations that share general characteristics but also have several differences even within their own regions/states. The analysis is simplistic and does not attempt to give a full conceptual scientific explanation of North-South knowledge gaps. The term literacy is used to denote the various competencies that citizens are required to master at a basic level. The most familiar meaning of literacy is the one related to basic reading and writing. However, literacy has become a common word to denote elementary skills that are needed by most, if not all, members of society, such as information literacy.
\end{abstract}

*Notes:

- Text originally presented as the Mortenson Distinguished Lecture, at the Mortenson Center for International Library Programs, University of Illinois at UrbanaChampaign.

- English editing by Carol Elliott and information reference assistance by Martha Herrera.

- Published in: 2006. "The Impact of Information Competencies on Socio-Economic Development in Southern Hemisphere Economies." In Martin, A. and Madigan, D. Digital Literacies for Learning. London: Facet 


\section{Information Development}

The development of nations can be measured according to their information progress because it shows how a country generates and uses knowledge, especially the printed type. Recorded knowledge has a production cycle: authors, inventors, and researchers generate information/knowledge in the form of articles, books, texts and patents that are then processed by publishers, database builders, webmasters and electronic media companies. Processed information is, in turn, stored and distributed by bookstores, libraries and other information providers to meet the demand (if the proper competencies to use information are present) of researchers, faculty, students, companies and society in general (Table 16.1). It is assumed that citizens need a working knowledge of the social, economic and political activities of their own country to improve their personal, family and business life. If this is true, it is also assumed that information literacy is a crucial set of skills that enable individuals to benefit from the wealth of knowledge available in paper or electronic format, and that these competencies are basically fostered by the countries' educational system.

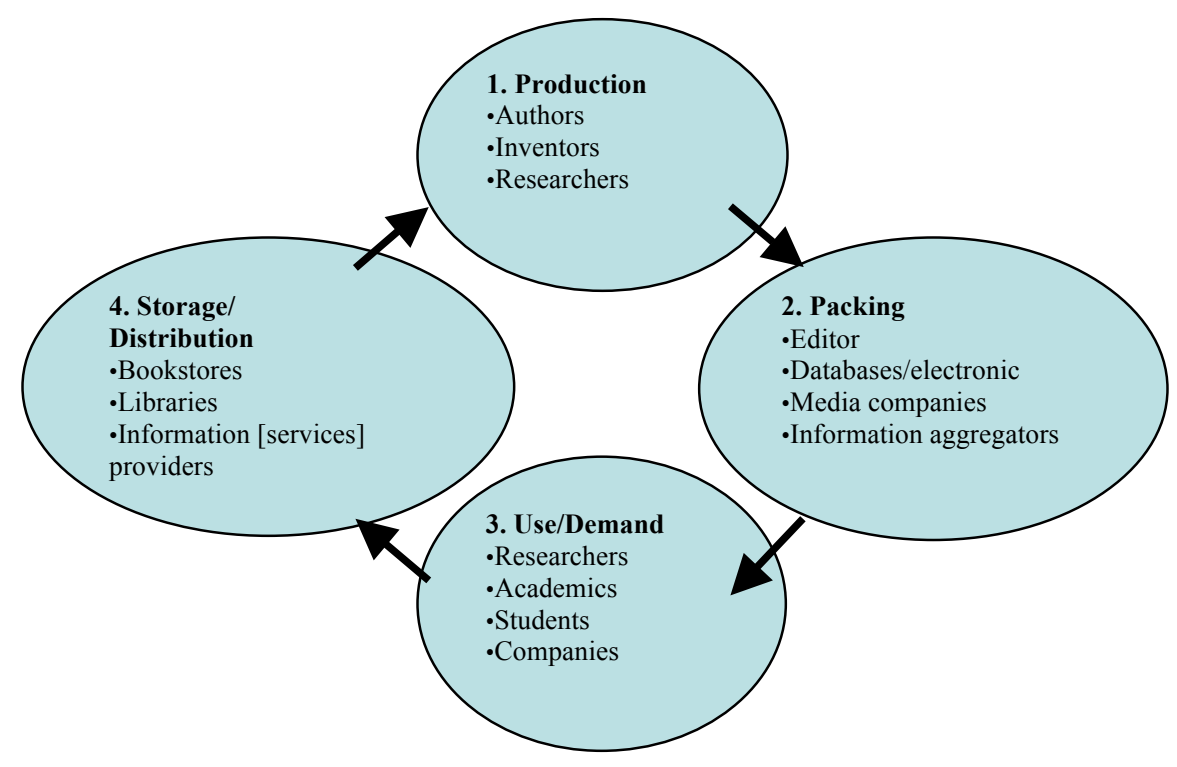




\subsection{Knowledge/Information Cycle}

This paper analyzes information development among regions and countries of the world, clustering nations according to their Gross National Product (GNP), as provided by the World Bank. The 2004 GNP per capita income classification for low-income countries is $\$ 825$ or less; lower middle-income, $\$ 826$ - $\$ 3,255$; upper middle-income, $\$ 3,256$ $\$ 10,065$; and high-income nations, $\$ 10,066$ or more. These figures and the rest of statistics used in this paper are taken as general indicators and have the limitation of obscuring national and local differences among countries. Some nations, especially the least-developed economies, face challenges in collecting and submitting statistics to United Nations Education Scientific Cultural Organization (UNESCO), the main provider of information and education-related data [4]. The term knowledge is used as synonymous with information, despite the fact that it has a different connotation. Few indicators are used to simplify the description of the knowledge gap between the Southern and Northern Hemispheres. Because the statistics were collected for different years, the reliability of indicators differs from country to country. Nevertheless, the figures do provide a pattern of the North-South knowledge gap, and the information literacy status in both regions. The grouping of nations follows the UNESCO Yearbook scheme, where, for example, Europe stands for Western and Eastern European nations; America covers North America (including Central America), South America and the Caribbean countries; and Oceania includes Australia, New Zealand and the Pacific islands. Southern Hemisphere countries are, on the other hand, roughly defined as those that are in the south and around the Equator. Following this grouping, most continents include developing economies.

\section{Knowledge / Information Production}


Knowledge is generated by authors and researchers, among other key players. The recording of scientific discoveries, technological developments and human experience in general, is normally measured by taking into account the number of patents and publications, such as reports, articles and books. Statistics for individuals engaged in research are also good indicators of knowledge-creation and information demand in a nation. The knowledge-generation differences among continents and countries are dramatic when these indicators are taken into account. African countries have fewer researchers $(71,000)$ than the developed country of Canada $(80,000)$. America (The three Americas), without the two major economies of Canada and the USA, also has an abysmal difference: 125,000 compared to more than 1,000,000 researchers for the two industrialized nations when the numbers for Canada and the USA are included. European countries and Japan and Asia generally rank high in number of researchers. However, the Asian group includes China and India, two highly populated nations that fare better in this indicator. If researchers are distributed per capita, however, China and India would rank low (Table 16.2).

\begin{tabular}{ll}
\hline Continent/Country & Researchers \\
\hline Africa & 71,308 \\
America* & 124,899 \\
Asia & $4,483,881$ \\
Europe & $1,892,307$ \\
Oceania & 60,066 \\
Canada & 80,510 \\
Japan & 651,099 \\
United States & 962700 \\
$16.2 \quad$ Researchers International Distribution (UNESCO [4]) \\
$\quad$ *Excludes USA and Canada
\end{tabular}

The discussed research indicators illustrate the world knowledge gaps and the potential implications for development. Research is an important activity in fostering socio- 
economic progress because it contributes to the generation of discoveries that industry can develop into new products and services to solve local problems. The leading role of the developed world in number of researchers gives them an advantage in the production of science and technology. Research activities are highly dependent on information competencies. Researchers must possess strong information skills to successfully benefit from the research work of others and to avoid inquiry overlap. Another strong indicator of knowledge production is the number of registered patents of countries. The developing countries generate $14 \%$ of patents compared to the striking figure of $86 \%$ for the highly-developed nations (Table 16.3).

\begin{tabular}{lll} 
& & \\
\hline Country / Region & Patents & Percentage \\
\hline USA & 44,609 & $40 \%$ \\
Germany & 15,269 & $13 \%$ \\
Japan & 13,531 & $12 \%$ \\
SUBTOTAL & 73,409 & $65 \%$ \\
United Kingdom & 6,274 & $5 \%$ \\
Other developed economies & 19,115 & $16 \%$ \\
SUBTOTAL & 25,389 & $86 \%$ \\
Rest of the world & 16,202 & $14 \%$ \\
Total & 115,000 & $100 \%$ \\
& 16.3 Patents (WIPO [6]) &
\end{tabular}

\section{Information Packaging}

The recording of information takes different forms, among them books, serials, databases, and websites. The recorded output of a country, i.e., publishing, reflects the national capability for knowledge packaging, an activity that is also heavily concentrated in the developed world. Scientific serials have been traditionally published in the developed world. The indicators of Table 16.4 show that Africa has slightly more than 
7,000 International Standard Serial Records (ISSN). Latin American countries have less than 30,000 ISSN records, while the USA holds the rather high figure of more than 160,000 serial records, and Canada more than 110,000 records [1]. Because journals represent a key form of knowledge encapsulation, the rather minimal number of serial records produced by the developing world, as cited for Africa and Latin America, is a strong indication of the information state of the countries (Table 16.4).

\begin{tabular}{ll}
\hline Continent/Country & ISSN Records \\
\hline Africa & 7,094 \\
Asia & 37,369 \\
Europe & 584,632 \\
South America / Caribbean & 27,842 \\
Oceanía & 51,691 \\
Canada & 111,918 \\
Japan & 30,947 \\
United States & 161,031
\end{tabular}

16. 4 Serial Titles (ISSN [1])

Another information medium, normally more accessible to the general population, is newspapers. They document the current, daily in most cases, information of a society and because dailies are cheaper than books and other serials, they are accessible to the general citizen. However, even with this indicator, the difference between developed and developing economies is significant. Circulation is 226 copies per 1,000 inhabitants in the developed countries, a large three-digit figure compared to the 60 copies that circulate in developing nations and the 8 copies that are produced in the least-developed countries. The newspaper-reading gap between North and South is similar to that of serial publications. Table 16.5 shows in greater detail the geographical differences between continents, where some of the largest economies represent the greatest newspaper demand. 


\begin{tabular}{llll}
\hline Continent/Region & $\begin{array}{l}\text { Number of } \\
\text { Dailies (000) }\end{array}$ & $\begin{array}{l}\text { Circ. Total } \\
\text { (millions) }\end{array}$ & $\begin{array}{l}\text { Per 1,000 } \\
\text { inhabitants }\end{array}$ \\
\hline World total & 8,391 & 548 & 96 \\
Africa & 224 & 12 & 16 \\
America & 2,939 & 111 & 141 \\
Asia & 3,010 & 229 & 66 \\
Europe & 2,115 & 190 & 261 \\
Oceania & 103 & 6.4 & 227 \\
Developed countries & 3,972 & 276 & 226 \\
Developing countries & 4,419 & 272 & 60 \\
Least developed & 172 & 3.9 & 8 \\
\multicolumn{2}{c}{ 16.5 Newspapers / Circulation (UNESCO [4]) }
\end{tabular}

Newspaper publication in paper is decreasing because leading newspapers have summaries or are published in full text on the Internet. However, they are still a good measure of information packaging in developing countries because news media is printed in traditional presses and the Internet is not yet readily available to all members of society.

\section{Storage and Distribution}

Information stocks are normally held and distributed in different types of places: e.g., bookstores, information centers and libraries, among other information distributors. Here libraries, library holdings, and computer networks are used as indicators because statistics were available for most countries. The most comprehensive library statistics are from national and public libraries. The holdings of the first type, national libraries, are excellent indicators of national information wealth, because national library collections 
represent the local information production in different media, not only printed material. In other words, the stocks of national libraries are the indicators of nationally produced information. These holdings vary dramatically from North to South. Europe has nearly $300,000,000$ volumes, a figure that looks astronomically large compared to Africa's holdings of less than 3,000,000 volumes. Asia, a highly populated continent, holds $46,000,000$ volumes, but a significant share is held by a single nation, Japan, the leading information economy in the Eastern Continent (Table 16.6). USA statistics were not available because of its non-UNESCO payment.

\begin{tabular}{lll} 
& & \\
\hline Continent/Country & Libraries & Volumes (000) \\
\hline Africa & 13 & 2,920 \\
America & 10 & 20,560 \\
Asia & 26 & 45,992 \\
Europe & 63 & 278,194 \\
Oceanía & 1 & 2,441 \\
Canada & 1 & 6,387 \\
Japan & 1 & 5,528
\end{tabular}

16.6 National Library Collections (UNESCO [4])

Public libraries, on the other hand, represent an indicator of information availability to the general citizen. Here, again, there are large disparities among regions. Africa accounts for 6,000,000 volumes, and the Latin American Continent holds 18,000,000 volumes compared to those of Europe with the outstanding figure of 2,500,000,000 volumes. Canada and Japan have 70,000,000 and nearly 200,000,000 volumes respectively. Asia ranks higher but its population is also high, so per capita indicators would be lower than those from Latin America. The difference in number of libraries or library service points, the prime centers to keep the public recorded knowledge, is also dramatic. The gap in public library service points follows the trend of holdings (Table 16.7). Library figures reflect information gaps among the hemispheres and regions, because the statistics are valid in the developed and developing world, unlike websites of 
other high-technology related information media that are mainly concentrated in the Northern Hemisphere.

\begin{tabular}{lll} 
& & \\
\hline Continent/Country & Libraries & Volumes (000) \\
\hline Africa & 358 & 6,271 \\
Asia & 22,741 & 597,394 \\
Europe & 127,271 & $2,568,421$ \\
Latin America & 2,060 & 18,231 \\
Canada & 1,045 & 70,077 \\
Japan & 2,172 & 195,390 \\
$\quad 16.7$ Public Library Collections (UNESCO [4])
\end{tabular}

The creation of home pages, portals and websites is the latest indicator used to identify the current information gaps throughout the world. The Internet, the electronic information highway, has become the most powerful world information repository. It amalgamates the production, packaging, storage and distribution of the information cycle. However, Internet is predominantly a Northern asset. Nearly all, i.e., 90\%, of Internet demand comes from developed countries, and $70 \%$ of computer servers are located in those countries. In addition, English is the lingua franca for Internet material: between 60 and $80 \%$ of the Internet records are in this language, a major information barrier for nonAnglo-Saxon societies. The enormous Internet gap between North and South is dramatic because the Internet is such an important tool for socio-economic and information development. The macro network comprises all the advantages that a nation requires to foster social progress. The differences between the Internet haves and the Internet have nots are higher than in the paper printed information indicators (Table 16.8). 


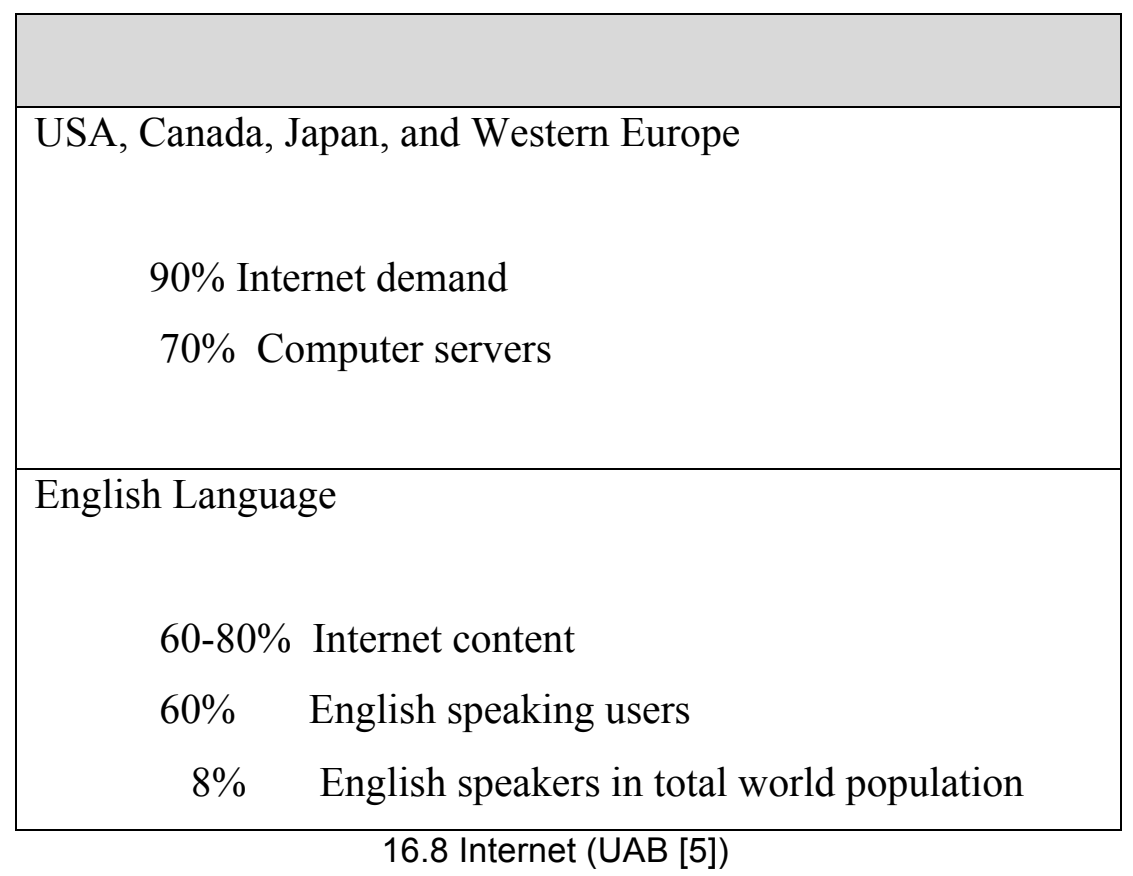

\section{Information use/demand}

The number of researchers can be used as a proxy for information demand, an indicator that was explained at the beginning of this section. As stated, there are striking differences in the number of researchers between the North and the South; figures for the North seem astronomically large when compared to the small number of people engaged in research in the developing nations of the South. The number of graduates could also be another good indicator of information demand but are not included in this document (See RICYT statistics [3]). Internet use is also another excellent indicator of how a country can access international information repositories. English native speakers, mainly citizens of the wealthy regions of the world, account for $8.3 \%$ of the total world population, but they represent nearly $60 \%$ of the Internet demand. Although the number of indicators used to describe international information demand is small, they do depict information use gaps among countries.

The international trends in the cycle of production, packaging, storage/distribution, and use/demand of information/knowledge illustrate, in general, the information and knowledge gaps between the two hemispheres. The ranking of countries in this cycle is 
closely related to the information competencies of a society. People who identify and succeed in achieving their information needs perform better in the different stages of the information/knowledge cycle. Countries with greater information demand and a greater supply of knowledge-recorded products are nations with greater information development. These nations are basically located in the northern part of the world, and they are, by analogy, the knowledge nations who lead in information competencies.

\section{The Knowledge Bridge}

Knowledge is the product of a cognitive process, where information becomes the key ingredient to enhance human perception, understanding, awareness, thinking, intelligence, and memory. Each of these cognitive stages relies or spins around information. Therefore, the competencies of searching, retrieving, and using recorded knowledge, i.e., information, is vital for individual and collective socio-economic development. These information competencies are mainly fostered by education, although parents and the work environment also play key roles. All citizens must develop information literacy skills to benefit from and participate in the knowledge cycle. For example, an information-literate worker who can learn constantly is able to adapt to short-term jobs that predominate in the current economy, including those from the upperindustrialized and service-oriented stratum of less-developed countries, sectors that share similar characteristics with more advanced economies. The workplace is moving from routine to rich-thinking activities; information literacy enables workers to respond to the life-long learning environment currently present in manufacturing and service industries. If education is an important process in an individual's personal and professional growth, including the development of information competencies, then developing economies may need to improve this crucial process in order to bridge the information competencies gap (Table 16.9). 
- Education enables people to be better citizens

- Education helps economic mobility of individuals

- Education determines national progress

- Education access is a challenge

- Education quality is even a greater challenge

- Information development is related to education

- Education fosters information competencies

16.9 Education - Development

\section{Conclusion}

According to the printed information indicators, less developed countries, mostly located in the Southern Hemisphere, have made limited information progress with a general correlation to their socio-economic development strata. The production and use or recorded knowledge, especially of the printed type, is low. The recorded knowledge production cycle of authors, inventors, and researchers indicates a low generation of information/knowledge, as indicated by the production of articles, books, texts and patents. Based on the statistics used in this paper, the information-processing infrastructure is also limited, e.g, publishers, database builders, webmasters and electronic media companies. The processes of storing and distributing information is, again, limited (bookstores, libraries and other information providers). On the other hand, the demand has the same trend when the number of researchers' statistics was analyzed. The most identifiable cause for such international information development gaps, although there could be many socio-economic reasons, is the limited information skills of citizens that prevent them from fully playing a role in the knowledge creation-use cycle. Limited information competencies may, in turn, be due to the quantity and quality of national educational systems, factors that were not analyzed in this paper. 
In conclusion, countries from the Southern Hemisphere could narrow the knowledge gap and achieve better information development if they were to improve their educational systems. It could be argued that reduced budgets are a barrier. However, the limitation of economic resources heightens the need for better education. Students are better educated with higher learning outcomes when learning outcomes are based on the development of competencies that, in turn, include the core information skills needed to access knowledge.

\section{References}

Kuhlthau, C. (1993) "Implementing a Process Approach to Information Skills: A study Identifying Indicators of Success in Library Media Programs" School Library Media Quarterly, 21, (1)

ISSN. Online at: http://www.issn.org:8080/English/pub/tools/statistics

RICYT. Online at: http://www.ricyt.org/Indicadores/Comparativos/18.xls.

UNESCO. http://www.uis.unesco.org/ev_en.php?ID=2867_201\&ID2=DO_TOPIC

Universitat Autónoma de Barcelona. (2004) "Importancia (y desigualdades) de los niveles de acceso a Internet" Hacia 2004: estudios interculturales, textos básicos para el forum 2004 (October, 1997 - August, 1998). Barcelona: Universitat Autónoma de Barcelona Online at: http://www.blues.uab.es/incom/2004/portada.html

World Intellectual Property Organization (WIPO) Online at: http://www.wipo.int/edocs/prdocs/es/2003/wipo_pr_2003_338.html 